\title{
Hybrid nanocomposites with enhanced visible light photocatalytic ability for next generation of clean energy systems
}

Chenbo Dong, Reem Eldawud, Alixandra Wagner, and Cerasela Zoica Dinu*

Department of Chemical Engineering, West Virginia University, 26505, USA

\section{Corresponding author:}

*Cerasela Zoica Dinu, Ph.D.

Associate Professor

Department of Chemical Engineering

West Virginia University

Benjamin M. Statler College of Engineering and Mineral Resources

PO Box 6102

Morgantown, WV, 26506, USA

E-mail: cerasela-zoica.dinu@mail.wvu.edu

Tel.: +1 3042939338

Fax: +1 3042934139 


\begin{abstract}
Heterogenous photocatalysis is widely used for waste-water treatment and degradation of pollutants and promises to advance the science of alternative materials with visible photo-excitations abilities. However, there are still fundamental material properties and processes that need to be understood in order to increase user-tailored catalytic systems' performance and efficiency, while ensuring their optimized reactivities and large-scale development and implementation.

Herein we developed graphene-based hybrid composites to be used as efficient nanocatalysts with increased ability to absorb visible light, that retain high corrosionresistance properties when used in solution, and provide energy levels that match their reduction and oxidation half-reactions. Using both photo-deposition and photoreduction methods, we first created platinum/tungsten trioxide conjugates with physico-chemical characteristics investigated by microscopical and spectroscopical analyses, and further decorated such conjugates onto graphene surfaces to create the hybrids. Our results demonstrate that the synthesized hybrids can degrade a model azo dye and further, show that graphene plays an important role in delaying electron transfer at its interface, with such effect being exploited for possible integration in the next generation of clean energy systems.
\end{abstract}

Keywords: graphene, hybrid, composite, delayed electron transfer 


\section{Introduction}

Active research is currently focusing on identifying technologies capable to increase the energy efficiency while reducing the human footprint and its impact on the environment. Relying on converting solar resources such as photons-toelectricity [1, 2] or photons-to-heat-to-electricity,[3, 4] such technologies use usertailored nanocatalytic systems and aim to improve energy generation.[5-7] However, there are still fundamental material' properties and processes that need to be understood in order to increase user-tailored catalytic systems' performance and efficiencies[8] while ensuring their optimized reactivities and large-scale integration.

Two main routes have been previously used to improve nanocatalyst's photocatalytic performance, i.e., increase of the electron-hole generation $[9,10]$ and delay of photo-induced charge recombination.[11, 12] Specifically, studies aiming to improve $\mathrm{TiO}_{2}$ reactivity under visible light irradiation proposed introducing suitable heteroatoms onto its structure[13, 14] and/or narrowing its band-gap.[15] However, such heteroatoms inserts need special technologies processing (e.g., sputtering,[16] ion implantation,[17] thermal treatments,[18] and others), are high energy cost and largely inefficient when yield is desired, thus with limited large-scale consumer and industrial implementation. Further, photocatalysis efficiency of the heteroatoms modified semiconductor materials may not be significantly improved when compared to their starting counterpart.[19] Complementary, $p-n$ junctions have been created in semiconductor nanomaterials such as molybdenum disulfide (MoS2)/ nitrogen-doped reduced graphene oxide (n-rGO)[20] or nickel oxide (NiO)/ titanium dioxide (TiO2)[21] to optimize photocatalytic activity,[22] while semiconductor nanoparticles-based surface heterostructures have been implemented to enhance separation of photogenerated carriers.[23-25] The resulting heterostructure interface was used to cage photoinduced electrons and consequently separate generated electron-hole pairs.[26] Additionally, n-n junctions heterostructures such as the ones found in structures of silver phosphate/ iron oxide $\left(\mathrm{Ag}_{3} \mathrm{PO}_{4} / \mathrm{Fe}_{2} \mathrm{O}_{3}\right)$, [27] silver vanadate/ zinc oxide $\left(\mathrm{Ag}_{3} \mathrm{VO}_{4} / \mathrm{ZnO}\right)$,[28] or zinc oxide/ silver bromide/ iron oxide/ silver vanadate $(\mathrm{ZnO} / \mathrm{AgBr} / \mathrm{Fe} 3 \mathrm{O} 4 / \mathrm{Ag} 3 \mathrm{VO} 4)[29]$ have recently been used to promote efficient separation of the charge carriers and generate high efficiency photocatalysis systems based on delayed electron-hole recombination effects. Further, it was also showed that the large surface area of graphene (GO) for instance, [30] its zero bandgap,[31] excellent electrical conductivity and ability to enhance electron transport,[32] its exceptional transparency,[33] and good chemical stability,[34] could lead to its integration as a promoter of photocatalytic reactions in heterostructures.[16]

Studies of $\mathrm{TiO}_{2}$ integrated with graphene for instance demonstrated nanohybrids with increased light absorption capability, all relative to bare $\mathrm{TiO}_{2}$ or $\mathrm{TiO}_{2}$-carbon nanotubes-based composites with the same carbon content.[35] It was also reported that when graphene oxide was wrapped with Ag or Ag-based suspensions (e.g., AgX, with $\mathrm{X}=\mathrm{Br}, \mathrm{Cl}$ ), high efficiency in removing organic pollutant methyl orange (an azo dye widely used in textiles and paper industries) under visible-light irradiation was achieved.[36] Further, when zinc oxide $(\mathrm{ZnO})$ nanoparticles were loaded onto graphene sheets, the resulting heterostructures exhibited significant increases in their photocatalyic activities as well as in the degradation ability of rhodamine B dye in water, all under UV irradiation.[37] However, the large band gap of such nanomaterials as well as considerable recombination of photogenerated electron-hole pairs limits their photocatalytic efficiency and thus applicability. Further, their activity is largely restricted to UV light irradiation which accounts for only about 3 - 
$5 \%$ of our solar spectrum[38] thus impeding their implementation. The next generation of efficient nanocatalysts will need to allow for an increased ability to absorb visible light and retain high corrosion-resistance properties when used in solution.

Among the visible active semiconductor nanoparticles, the optical[39] and electronic properties,[40] small band gap $(2.4 \mathrm{eV}-2.8 \mathrm{eV}),[41,42]$ high oxidation power in the valence band,[43] low production cost, reduced toxicity and increased stability [41, 42] make tungsten trioxide $\left(\mathrm{WO}_{3}\right)$ a potential candidate for catalyticbased applications[43-48] to be used for water treatment[47] or clean energy generation.[46, 49, 50] However, because of its low conduction band,[43] high and fast recombination of photo generated electron-hole pairs, pure $\mathrm{WO}_{3}$ does not show high photocatalytic ability which limits its implementation. For this nanocatalysts to reach its potential in consumer applications, strategies that enhance its photocatalytic activity under visible light should potentially involve a variety of combinatorial techniques that allow for effective modifications approaches, and doping effects to lead to increased photon absorption efficiency and reactivity.

Herein we propose to synthesize the next generation of visible light absorbing heterostructures based on $\mathrm{WO}_{3}$ and $\mathrm{GO}$ for efficient photodegradation of model compound, rhodamine $\mathrm{B}$. Using liquid phase photoreduction, [44] we designed $\mathrm{WO}_{3-}$ based nanoparticles/ GO heterostructure and evaluated their efficiency for stable photocatalysis. $\mathrm{WO}_{3}$ was chosen as starting material based on its above properties and catalytic promises as well as its increased charge separation efficiency[51] and remote oxidation activity when under visible light irradiation.[52] GO was chosen as a template based on its two-dimensional crystalline structure that can ensure efficient electron transfer at nanointerfaces.[20] Rhodamine B[53,54] was chosen as the model system to demonstrate high photodegradation efficiency because of its high stability under visible light irradiation and reduced biodegradability.[55] This is especially important in the context of heterogenous photocatalysis being widely used for wastewater treatment, with previous studies being based on either traditional Ti[56] or $\mathrm{ZnO}$ [57] catalysts, tantalates [58] or germanates. [59] Further, the focus on rhodamine $\mathrm{B}$ is also supported by previous studies that showed that the dye is an active carcinogen,[60] more difficult to remove than other dyes such as methyl orange or methylene blue.[61-64] Our research aims to unravel the fundamental mechanisms, properties and processes that allow for increased performance, reliability, competitiveness and implementation of $\mathrm{WO}_{3}-\mathrm{GO}$ heterostructures in robust architectures while preserving their performance, all under visible light. 


\section{Materials and Methods}

\section{Synthesis of Graphene Oxide}

Graphene oxide (GO) was synthesized using the established Hummer method and natural graphite powders.[65, 66] In a typical experiment, $1 \mathrm{~g}$ graphite powder (Acros Organics), $0.5 \mathrm{~g}$ sodium nitrate (Acros Organics, 99\%) and $25 \mathrm{~mL}$ concentrated sulphuric acid (96.4\%, Fisher Scientific) were mixed into a $250 \mathrm{~mL}$ flask placed in an ice bath. Subsequently, $3 \mathrm{~g}$ of potassium permanganate powder (Fisher Scientific) was slowly added and the mixture was continuously stirred and cooled with fresh ice for 2 $\mathrm{h}$ in a water bath maintained at a temperature below $20^{\circ} \mathrm{C}$. After time elapsed, the mixture was transferred to another water bath having a temperature of about $35^{\circ} \mathrm{C}$ and stirred for an additional $0.5 \mathrm{~h}$. Next, $46 \mathrm{~mL}$ of deionized (Di) water were added slowly to the mixture, and subsequently the flask was placed at $98{ }^{\circ} \mathrm{C}$ for $15 \mathrm{~min}$. Lastly, $140 \mathrm{~mL}$ of Di water followed by $10 \mathrm{~mL}$ of $30 \%$ hydrogen peroxide $\left(\mathrm{H}_{2} \mathrm{O}_{2}\right)$ aqueous solution (Fisher Scientific) were added. The obtained solid product was isolated by centrifugation, washed several times with $5 \%$ hydrogen chloride $(\mathrm{HCl})$ solution (diluted from $37.3 \%$, Fisher Scientific), Di water and ultimately dried under the vacuum.[67]

\section{Synthesis of Conjugates and Hybrid Materials}

To create tungsten trioxide $\left(\mathrm{WO}_{3}\right)$ conjugate, a photodeposition method was used. Briefly, $500 \mathrm{mg}$ of $\mathrm{WO}_{3}$ nanoparticles (99 \%, Sky Spring Nanomaterials Inc) were dispersed in $50 \mathrm{~mL}$ Di water by ultrasonication. Subsequently, $10 \mathrm{mg}$ GO were added to the solution, with the mixture being stirred overnight at room temperature and then filtered and washed with $1 \mathrm{M} \mathrm{HCl}$ solution containing $1 \% \mathrm{H}_{2} \mathrm{O}_{2}$ in Di water to remove impurities.[68] The wet powder was subsequently suspended in a solution containing $95 \mathrm{~mL}$ Di water and $5 \mathrm{~mL}$ methanol (99\%, Fisher Scientific) and irradiated using a $500 \mathrm{~W}$ lamp for a $2 \mathrm{~h}$ period to produce reduced $\mathrm{WO}_{3}-\mathrm{GO}$ hybrids, subsequently denoted as $\mathrm{WO}_{3} / \mathrm{r}-\mathrm{GO}$.

In order to create platinized $\mathrm{WO}_{3}$ and platinized $\mathrm{WO}_{3} / \mathrm{r}-\mathrm{GO}\left(\mathrm{Pt} / \mathrm{WO}_{3}\right.$ and $\mathrm{Pt} /$ $\mathrm{WO}_{3} / \mathrm{r}$-GO respectively) hybrids, a photocatalytic deposition/ reduction approach of Pt onto $\mathrm{WO}_{3} / \mathrm{r}-\mathrm{GO}$ was performed. Briefly, the method was achieved under visible light by using a $500 \mathrm{~W}$ lamp and chloroplatinic acid (MP Biomedicals, LLC) in methanol solution ( $5 \mathrm{~mL}$ methanol, $99 \%$ in $95 \mathrm{~mL}$ Di water). The weight of Pt was chosen relative to lead to $2 \mathrm{wt} \%$.[69]

\section{Samples Characterization}

The morphologies of the samples were evaluated using a Hitachi S-4700 Field Emission Scanning Electron Microscope (SEM) and a JEM-2100F Transmission Electron Microscope (TEM) respectively. For SEM characterization, samples (1 $\mathrm{mg} / \mathrm{mL}$ in Di water) were dried under vacuum on silica wafers and imaged using a field emission gun operating at $10 \mathrm{kV}$.

Energy dispersive X-ray analysis (EDX) was used for quantitative elemental analysis. The experiments were performed on a Hitachi S-4700 Field Emission Scanning Electron Microscope (USA) with a S-4700 detector combining secondary (SE) and backscattered (BSE) electron detection (all in a single unit), operating at 20 $\mathrm{kV}$. Results are presented as a map of element distribution.

Analysis of particle size distribution was performed using a dynamic light scattering instrument (DLS, DelsaTM Nano Particle Analyzer Beckman Coulter, Germany). The DLS measurement used Stokes-Einstein equation to yield the radius or the diameter of the samples. Briefly, suspensions of $\mathrm{WO}_{3}$ and $\mathrm{Pt} / \mathrm{WO}_{3}$ were 
prepared in Di water at a concentration of $100 \mu \mathrm{g} / \mathrm{mL}$ and the mean particle diameter was calculated by analyzing the intensity, volume, and number distribution data collected for each one of the samples.

Raman spectroscopy (Renishaw InVia Raman Spectrometer, CL532-100, 100 $\mathrm{mW}$ ) allowed determination of the physical and chemical characteristics of the samples. Briefly, powders were deposited on glass slides (Fisher, $25 \times 75$ x $1 \mathrm{~mm}$ ) and irradiated through a $20 \mathrm{X}$ microscope objective using an Argon ion (Ar+) laser beam with a spot size of $<0.01 \mathrm{~mm}^{2}$ and operating at $514.5 \mathrm{~nm}$. Scan were performed in the 100 to $3200 \mathrm{~cm}^{-1}$ ranges and low laser energy (i.e., $<0.5 \mathrm{mV}$ ) with short exposure times $(10 \mathrm{~s})$ were used to prevent unexpected heating effects of the samples.

A digilab FTS 7000 Fourier transmission infrared spectroscope (FTIR) with an attenuated total reflectance (ATR) unit and a diamond crystal was employed to investigate the chemical characteristics of the samples. For this, $200 \mathrm{mg}$ of the individual sample were pressed into barium sulfate paste (Shimadzu Corporation) to form a solid pellet subsequently used under FTIR conditions. Spectra ranging from 750 to $4000 \mathrm{~cm}^{-1}$ were collected using a Shimadzu 2550.

Ultraviolet (UV)-visible (VIZ) spectra were recorded using in the diffuse reflectance mode a Shimadzu 2550 UV-visible spectrometer equipped with an integrating sphere (UV 2401/2, Shimadzu).

PHI Versaprobe 5000 Scanning X-Ray Photoelectron Spectrometer (XPS, Physical Electronics) was used to examine the electronic state of the sample (i.e., for the presence of $\mathrm{Pt}, \mathrm{C}, \mathrm{W}, \mathrm{O}$ elements respectively). The $\mathrm{C} 1 \mathrm{~s}$ peak at $284.6 \mathrm{eV}$ was used as reference and to calibrate the binding energy of the different elements identified in the spectrum.[70]

\section{Photocatalytic Degradation Tests}

Synthesized samples $\left(\mathrm{WO}_{3}, \mathrm{Pt} / \mathrm{WO}_{3}, \mathrm{WO}_{3} / \mathrm{r}-\mathrm{GO}\right.$, or $\mathrm{Pt} / \mathrm{WO}_{3} / \mathrm{r}-\mathrm{GO}$ respectively) were dispersed in $20 \mathrm{~mL}$ rhodamine B solution $(10 \mu \mathrm{g} / \mathrm{mL}$, Fisher Scientific) for a final concentration of $2 \mathrm{mg} / \mathrm{mL}$. The mixture was stirred continuously for $0.5 \mathrm{~h}$ and subsequently exposed to a visible light lamp $(500 \mathrm{~W})$, at room temperature for 360 min, while under shaking. At each given time interval $(10,30,60,180$, or $360 \mathrm{~min}$ respectively), $1 \mathrm{~mL}$ of the rhodamine $\mathrm{B}$ solution containing nanoparticles was isolated and centrifuged at $5000 \mathrm{rpm}$ for $1 \mathrm{~min}$, then $500 \mu \mathrm{L}$ supernatant was isolated and monitored using an Evolution $300 \mathrm{UV}$-Vis spectrophotometer that allowed for absorption changes at $554 \mathrm{~nm}$ to be recorded.[71] A blank group (Di water mixed with nanoparticles however not irradiated) was used as control for each time point.

Rhodamine $\mathrm{B}$ degradation efficiency was expressed as $\mathrm{C} / \mathrm{Co}$, where $\mathrm{C}$ was the concentration of rhodamine $\mathrm{B}$ at different time intervals and Co was its starting concentration; the lower $\mathrm{C} / \mathrm{Co}$, the higher the degradation efficiency, where the concentration of rhodamine $\mathrm{B}$ was obtained by converting the absorption data using the Beer-Lambert law.[72]

\section{Kinetic Parameters Calculation}

Knowing that the photodegradation of rhodamine B follows roughly a pseudo first order reaction, [73] the kinetic of photodegradation reaction was evaluated using the following equation:

$\ln (\mathrm{C} / \mathrm{Co})=-\mathrm{kt}$, where $\mathrm{t}$ was the reaction time and $\mathrm{k}$ is the reaction rate, as calculated from the slope of different $\ln (\mathrm{C} / \mathrm{Co})$ versus $t$ curves. 


\section{Statistical Analyses}

The photocatalytic degradation tests were repeated 6 times and the analyses are presented as mean \pm standard deviation. The average size of nanoparticles is also presented as mean \pm standard deviation with at least 15 individual nanoparticles being evaluated in TEM to obtain particle average size. 


\section{Results and Discussion}

We used photodeposition of platinum $(\mathrm{Pt})$ onto tungsten trioxide $\left(\mathrm{WO}_{3}\right)$ nanoparticles to generate $\left(\mathrm{PtWO}_{3}\right)$ conjugates. Previous research has showed that $\mathrm{PtWO}_{3}$ has enhanced photoreaction ability mainly due to its improved multi-electron $\mathrm{O}_{2}$ reduction,[74] with the presence of $\mathrm{Pt}$ promoting photo-irradiated electrons to react efficiently with $\mathrm{O}_{2}$ before being trapped onto the $\mathrm{WO}_{3}$ surface (Scheme 1).

The topography and morphology of the conjugates was first evaluated using Scanning Electron Microscope (SEM) and high-resolution Transmission Electron Microscopy (HR-TEM) and compared to that of the starting materials. SEM analyses identified porous structures and nanoparticles of spherical geometries (Figure S1), while TEM allowed for both size and crystalline lattice spacing determination. Specifically, evaluation of the $\mathrm{WO}_{3}$ revealed size distributions between 20 to $100 \mathrm{~nm}$ (average of $61 \pm 34 \mathrm{~nm}$ ) and crystalline lattice spacing of about $0.38 \mathrm{~nm}$ corresponding to the (020) plane (Figure 1a).[75] Analyses also showed that the $\mathrm{PtWO}_{3}$ conjugates were different than their starting $\mathrm{WO}_{3}$ counterparts and were formed either from small (ranging from 5 to $20 \mathrm{~nm}$ ) or large (20 to $100 \mathrm{~nm}$ ) conglomerates (Figure 1b). HR-TEM identified the (111) lattice plane of Pt and its interplanar spacing of $0.23 \mathrm{~nm}$ (Figure 1c), as well as revealed the non-uniform distribution of the $\mathrm{Pt}$ at the interface with the $\mathrm{WO}_{3}$ nanoparticle template. Such distribution was presumably associated with Pt's inclination to deposit and interact at the small facets or edges, the ones mostly corresponding to the (020) crystalline structure of the template, with previous research indicating that photodeposition of $\mathrm{Pt}$ is induced by direct adsorption of ions and the surface charge respectively.[45]

Energy Dispersive X-ray Spectroscopy (EDX) also confirmed the non-uniform distribution of the elements and their random concentrations within the samples (Figure S2). Lastly, dynamic light scattering (DLS) analyses showed that the size of the nanoparticles was not significantly changed by the deposition of $\mathrm{Pt}$ when compared to the pristine counter samples (Figure S3, Table S1). However, the calculated nanoparticles average size in DLS was larger than the one observed in TEM, and was presumably due to the degree of agglomeration as resulted from the dispersion of the nanoparticles in water.[76]

Secondly, hybrid materials based on reduced graphene (r-GO) and $\mathrm{WO}_{3}$ or $\mathrm{PtWO}_{3}$ conjugates respectively, were obtained by photodeposition under visible light as previously described.[77] Raman spectroscopy confirmed the generation of the $r$ GO-based hybrid materials; specifically, peaks around $810 \mathrm{~cm}^{-1}$ and $710 \mathrm{~cm}^{-1}$ which were attributed to the stretching of the $\mathrm{O}-\mathrm{W}-\mathrm{O}$ bonds, as well as peaks at $328 \mathrm{~cm}^{-1}$ and $270 \mathrm{~cm}^{-1}$ which were related to the bending vibration of the $\mathrm{W}-\mathrm{O}-\mathrm{W}$ bonds were noted.[78] Peaks below $200 \mathrm{~cm}^{-1}$ were also observed and were generally associated with the vibrations in the lattice modes of the $\mathrm{WO}_{3}$-based nanoparticles, while the $\mathrm{D}$ peak around $1350 \mathrm{~cm}^{-1}$ was related to the disorder induced in the carbon (C) structure by the photoreduction of the r-GO surface. Complementary, the G peak around 1600 $\mathrm{cm}^{-1}$ was associated with $\mathrm{sp}^{2} \mathrm{C}$ vibration.[79] The relative intensity (I) of D to $\mathrm{G}$ peaks (an indicator of the disorder degree in the C-based hybrids[76]) was 0.96 and 0.97 for the $\mathrm{WO}_{3} / \mathrm{r}-\mathrm{GO}$ and $\mathrm{PtWO}_{3} / \mathrm{r}-\mathrm{GO}$ respectively, all relative to the $\mathrm{r}-\mathrm{GO}(0.83)$ used as control. The increase in $\mathrm{I}_{\mathrm{D}} / \mathrm{I}_{\mathrm{G}}$ ratio indicated the higher degree of disorder upon formation of the hybrid, as well as suggested decreased regular $\mathrm{sp}^{2} \mathrm{C}$ structure upon the photoreduction of GO.[80]

Attenuated Total Reflectance (ATR) Fourier Transform Infrared spectroscopy (FTIR) allowed direct analyses of the hybrid chemical signatures, through Fick's 
second law. Specifically, in Figure $2 \mathrm{~b}$ the peak around $649 \mathrm{~cm}^{-1}$ was attributed to $\mathrm{W}$ $\mathrm{O}-\mathrm{W}$ stretching mode and was shifted towards lower wavelength for the r-GO-based hybrid materials when compared to their counterparts. Analyses also showed that the principal vibration peaks around $728 \mathrm{~cm}^{-1}$, which were related to the O-W-O stretching mode,[81] seemed to disappear for the $\mathrm{r}-\mathrm{GO}$ related samples $\left(\mathrm{WO}_{3} / \mathrm{r}-\mathrm{GO}\right.$ and $\mathrm{PtWO}_{3} / \mathrm{r}-\mathrm{GO}$ respectively) possibly indicating that a strong interaction was formed between $\mathrm{r}-\mathrm{GO}$ and the $\mathrm{WO}_{3}$ interfaces; such interactions could have changed sample's surface chemistry. The peak around $1053 \mathrm{~cm}^{-1}$ was attributed to the carboxylate group formed onto the functionalized $\mathrm{r}-\mathrm{GO}$ surface, while the new small peak at around $1565 \mathrm{~cm}^{-1}$ was indexed to the $\mathrm{C}=\mathrm{C}$ skeletal vibration model in the $\mathrm{r}$ GO structures.[82] The additional peak at $3430 \mathrm{~cm}^{-1}$ in the r-GO-based hybrid was presumably due to $\mathrm{O}-\mathrm{H}$ vibration and may be possibly associated with the photoreduction procedure used during the hybrids formation.[83] Analyses also revealed that the peaks related to the $\mathrm{r}-\mathrm{GO}$ structure were relatively weaker when compared to the other peaks, thus confirming previous results recorded for $\mathrm{r}-\mathrm{GO}$ sheets in hybrid nanocomposites with low amount of graphene.[84]

After ultraviolet-visible spectrophotometry (UV-VIS) analyses in the $380-800 \mathrm{~nm}$ scans, a redshift (shift towards higher wavelengths) was observed for all the samples $\left(\mathrm{WO}_{3}, \mathrm{PtWO}_{3}, \mathrm{WO}_{3} / \mathrm{r}-\mathrm{GO}, \mathrm{PtWO}_{3} / \mathrm{r}-\mathrm{GO}\right.$ respectively) being tested (Figure $\left.2 \mathrm{c}\right)$. The shift for the $\mathrm{PtWO}_{3} / \mathrm{r}-\mathrm{GO}$ hybrids was attributed to the chemical bonding between $\mathrm{WO}_{3}$ and the specific sites of $\mathrm{C}$ onto r-GO's.[85] Furthermore, the optical absorption edges of the $\mathrm{WO}_{3}, \mathrm{PtWO}_{3}, \mathrm{WO}_{3} / \mathrm{r}-\mathrm{GO}$, or $\mathrm{PtWO}_{3} / \mathrm{r}-\mathrm{GO}$ showed cut offs at 469, 470, 471 , and $473 \mathrm{~nm}$ respectively. Such cut offs corresponded to optical band gaps of 2.64, 2.64, 2.63, and $2.62 \mathrm{eV}$ respectively as calculated using:

$$
\text { E ev }=h * \text { cwave length }(\mathrm{nm})=1240 \text { wave length }(\mathrm{nm}) \text {, }
$$

where $\mathrm{h}$ is Planck's constant and $\mathrm{c}$ is the speed of light.[86]

$\mathrm{X}$-ray Photoelectron Spectroscopy (XPS) revealed peaks located at 71.2 and 74.5 $\mathrm{eV}$ in the $\mathrm{PtWO}_{3}$ and $\mathrm{PtWO}_{3} / \mathrm{r}-\mathrm{GO}$ samples, which were attributed to the $\mathrm{Pt}(0)(4 \mathrm{f} 7 / 2)$ and $\mathrm{Pt}(0)$ (4f 5/2) respectively,[87] thus confirming Pt loading onto the r-GO template (Figure 3a).[85] Complementary, characteristic peaks around 284.6 and $287.0 \mathrm{eV}$ were observed for the r-GO-based hybrids and were attributed to $\mathrm{C} 1 \mathrm{~s}$ of the $\mathrm{C}-\mathrm{C}$ and the $\mathrm{C}-\mathrm{O}$ respectively (Figure 3b),[48] further confirming the decoration of the nanoparticles. Analyses also showed that the $\mathrm{W}$ atoms were in the formal valence band +6 ,[78] with the observed binding energy peaks at around 35.8 and $37.8 \mathrm{eV}$ being associated with spin-orbit splitting of the $\mathrm{W} 4 \mathrm{f} 7 / 2$ and $\mathrm{W} 4 \mathrm{f5} / 2$ respectively (Figure 3c).[88] Lastly, in the O core level XPS spectrum (Figure 3d), the $530.8 \mathrm{eV}$ peak corresponding to the O1s[89] showed no changes in all the samples being investigated, thus indicating that $\mathrm{Pt}$ coating and $\mathrm{r}-\mathrm{GO}$ modification, while changing the surface chemical/physical properties of the hybrids did not affect their crystalline structure.

To evaluate the photocatalytic performance of the user-synthesized nanoparticles or resulting hybrids, we monitored the degradation of rhodamine $\mathrm{B}$ under visible light irradiation and at room temperature (Figure $4 a$ ). In control, the changes in the $C / C_{o}$ of rhodamine $\mathrm{B}$ in aqueous solution and in the absence of any sample respectively were also monitored, with $\mathrm{C}$ and $\mathrm{C}_{\mathrm{o}}$ representing the concentration of rhodamine $\mathrm{B}$ at times $\mathrm{t}$ and 0 respectively. Typical results showed photocatalytic activities for all the sample, with the degradation of rhodamine B being sample dependent. Specifically, after $6 \mathrm{~h}$ 
of visible light irradiation, the $\mathrm{C} / \mathrm{Co}$ percentage of rhodamine $\mathrm{B}$ without addition of nanoparticles was about $83 \%$ of its initial concentration before visible light irradiation. However, addition of $\mathrm{WO}_{3}$ to the rhodamine $\mathrm{B}$ solution induced about $69 \%$ decomposition after $6 \mathrm{~h}$ visible light irradiation, when compared to the initial rhodamine $\mathrm{B}$ solution without addition of nanoparticles. Furthermore, addition of Ptcoated or r-GO modified hybrid materials $\left(\mathrm{PtWO}_{3}, \mathrm{WO}_{3} / \mathrm{r}-\mathrm{GO}\right.$, or $\left.\mathrm{PtWO}_{3} / \mathrm{r}-\mathrm{GO}\right)$ led to a more significant enhancement in the photodegradation ability, with the rhodamine B solution being completely decomposed in the presence of the $\mathrm{PtWO}_{3} / \mathrm{r}-\mathrm{GO}$ hybrids after only $3 \mathrm{~h}$.

The increased photocatalytic ability of the Pt-based samples is presumably due to the Pt serving as electron accepting species to promote the formation of superoxide radical anions or retard electron-hole recombination at the $\mathrm{WO}_{3}$-based interfaces.[90] Further, the increased catalytic ability of the r-GO-based hybrids when compared with pure $\mathrm{WO}_{3}$ is presumably due to the chemical coupling between $\mathrm{WO}_{3}$ nanoparticles and specific sites of C onto r-GO's, which could thus enhance the hybrid's ability for organic dye degradation by increasing dye's adsorptivity at the hybrid interface[91] and improving photogenerated charge carrier lifetime, or by boosting a two-electron reduction of $\mathrm{O}_{2}$ to $\mathrm{H}_{2} \mathrm{O}_{2}$ in solution. [92] The enhanced photocatalytic ability of the $\mathrm{r}-$ GO-based hybrids could also derive from the strong coupling between the r-GOdecorated surfaces, which can promote interfacial electron transfers to effectively reduce electron-hole pair recombination rates[93] and thus increase the amount of radical components with strong oxidation capability (for instance hydroxyl radicals; Scheme S1) and lifetime of charge carriers upon their formation.[94]

Previous results support our studies and show that carrier motility, the ability to photogenerate electron-hole pairs, as well as the efficiency of recombination could affect nanoparticle photocatalytic performance.[86] For instance, Xu et al., generated GO-based hybrid containing $\mathrm{ZnO}$ nanoparticles and showed significant enhancement of their photocatalytic performance as resulted from the increased migration efficiency of photo-generated electrons and the inhibition of charge carriers recombination at interfaces.[24] Similar results were obtained by Meng et al., which combined $p$-type $\mathrm{MoS}_{2}$ nanoplatelets with n-type nitrogen-doped r-GO ( $n$-r-GO) to generate $p-\mathrm{MoS}_{2} / n-\mathrm{r}-\mathrm{GO}$ heterostructures with significantly enhanced photocatalytic activity in water. Authors also showed that such heterostructures had improved charge generation and suppressed charge recombination at their junction.[20] Similarly, Sang et al., fabricated $\mathrm{TiO}_{2} / \mathrm{r}-\mathrm{GO}$ nanosheets via in situ photochemical reduction and showed that the hybrid interfaces could drain the excited electrons from the $\mathrm{TiO}_{2}$ to increase charge-carrier separation and enhance hybrid's photocatalytic performance.[95] Lastly, surface plasmon resonance (SPR) was proposed to extend visible light response and increase the absorption capacity and light-absorption efficiency of such materials.[96] In particular, studies showed improvement of quantum yield, extension of the visible light response, and enhancement of both the absorption capacity and localized electric field at nanointerfaces.[97, 98]

Linearized reaction kinetic data for rhodamine B are shown in Figure $4 \mathrm{~b}$. Analyses showed that the photocatalytic degradation obeyed first order kinetics with the calculated values of reaction rate for $\mathrm{WO}_{3}, \mathrm{PtWO}_{3}, \mathrm{WO}_{3} / \mathrm{r}-\mathrm{GO}$, and $\mathrm{PtWO}_{3} / \mathrm{r}-\mathrm{GO}$ being $3.17 \times 10^{-3} \mathrm{~min}^{-1}, 4.64 \times 10^{-3} \mathrm{~min}^{-1}, 7.22 \times 10^{-3} \mathrm{~min}^{-1}$, and $2.19 \times 10^{-2} \mathrm{~min}^{-1}$ respectively. It was also observed that the $\mathrm{PtWO}_{3} / \mathrm{r}-\mathrm{GO}$ hybrids had a significant increase in their photocatalytic activities when compared to the other samples being tested.

Our results are comparable with the ones obtained upon photodegradation of 
rhodamine $\mathrm{B}$ by macroporous $\mathrm{TiO}_{2}$ particles (i.e., reaction rate close to $3.0 \times 10^{-2} \mathrm{~min}^{-}$ ${ }^{1}$ ), which are known to exhibit enhanced photodegradation ability when compared to dense $\mathrm{TiO}_{2}$ (reaction rate close to $1.0 \times 10^{-2} \mathrm{~min}^{-1}$ ).[99] Such results are presumably due to the increased surface area of these nanoparticles when compared to their bare counterparts. Further, in our study, the degradation reaction rate observed for the $\mathrm{PtWO}_{3} / \mathrm{r}-\mathrm{GO}$ under visible light was around 14 times higher than the one observed in the presence of $\mathrm{TiO}_{2}$ under $\mathrm{UV}\left(0.6 \times 10^{-3} \mathrm{~min}^{-1}\right)$ or VIS $\left(1.6 \times 10^{-3} \mathrm{~min}^{-1}\right)$ irradiation.[100] This demonstrated that the synthesized $\mathrm{PtWO}_{3} / \mathrm{r}-\mathrm{GO}$ hybrids could compete in a more efficient manner with the currently available enhanced $\mathrm{TiO}_{2}$ porous semiconductor materials for photoreaction and removal of rhodamine $\mathrm{B}$, all under visible light. The higher efficiency is presumably due to combination of semiconductor nanoparticles and r-GO interfaces which could reduce electron-hole pair recombination rates, as well as increase the lifetime of charge carriers to promote generation a stronger oxidation capabilities and thus organic dye degradation. While our rates of degradation are currently lower than the ones observed upon the evaluation of $\mathrm{TiO}_{2} / \mathrm{GO}$ hybrid materials exposed to UV (i.e., $0.2 \mathrm{~min}^{-1}[93,95]$ ), they are still very encouraging since they are obtained all under normal visible radiation and at lower intensity.

We believe that our results could be extended to include degradation of other dyes, namely methyl orange and methylene blue normally present as soluble molecules or ions in contaminated waters.[61, 101] Such dyes are known to have lower adsorption capacities than rhodamine B, as shown by the analysis of Aanadurai et al.,[61] thus their photodegradation by our user-tailored systems should be more efficient. Such hypothesis is supported also by previous studies that have showed that the reaction rate constant for rhodamine $\mathrm{B}$ is around $.0058 \mathrm{~min}^{-1}$ on a hypercrosslinked polymeric adsorbent in aqueous solution, which is almost the double compared to $.0028 \mathrm{~min}^{-1}$ for methyl orange.[61, 62, 102] Although a direct comparison between these studies[61-64] is rather difficult because of the differences in the working conditions and sample preparation, it is evident that optimum usertailored properties and sample characteristics will largely influence the ability to photodegrade any of the proposed tested dye.

Our study showed that the photodegradation ability of hybrids depends on their heterostructure and their physico-chemical properties, with the optimum photocatalytic interface and its characteristics being influenced by the morphological, topographyical, and chemical signatures of the individual sample being templated. As such, our analyses may hint that the fundamental mechanisms that drive photocatalysis at such user-formed heterointerfaces relate to the available area for reaction and the electron-hole pair recombination rate. Thus, our study provides insight into the development of the next generation of visible light absorbing efficient photocatalysts to be used for consumer applications. In particular, one could control $\mathrm{Pt}$ decoration as well as Pt distribution to ensure uniform coating of the GO templates to thus increase energy transfer and carrier mobility at such interfaces for high efficiency, long lifetime energy generation to be used in the next generation of energy storage and conversion devices (i.e., solar cell, fuel cell electrode).

\section{Conclusion}

We synthesized $\mathrm{WO}_{3}$-based nanoparticles $\left(\mathrm{WO}_{3}\right.$ and $\left.\mathrm{PtWO}_{3}\right)$ and r-GO-based hybrid materials using photoactivation and photoreduction methods. The $\mathrm{WO}_{3}$ nanoparticles dispersed onto the r-GO templates formed hybrid materials as confirmed by a combination of analytical analyses. The existence of r-GO with zero 
bandgap improved hybrid material's ability to separate carriers and to delay electron/hole pair recombination thus leading to enhanced photocatalytic activity when degradation of rhodamine $\mathrm{B}$, a cationic dye used as model system, was considered. Our facile synthesis approach provides a facile methodology for the preparation of semiconductor/graphene-based hybrid functional materials with enhanced photocatalytic efficiency to be used for water treatment and clean energy generation.

\section{Acknowledgements}

This work was supported by National Science Foundation (NSF) grant 1454230. The authors thank shared facilities and Dr.s Weiqiang Ding and Marcela Redigolo for their assistance with XPS and HRTEM analyses, and Dr.s Jiangtian Li, Peng Zheng, Dr. Nianqiang Wu for allowing usage of the UV-Vis spectrophotometer and analyses software. 


\section{Figures Caption}

Figure 1: High Resolution Transmission Electron Microscopy (HR-TEM) images of (a) $\mathrm{WO}_{3}$; (b) $\mathrm{Pt} / \mathrm{WO}_{3}$; and (c) $\mathrm{WO}_{3} / \mathrm{r}$-GO samples. Samples analyses allowed for size distribution and crystalline lattice spacing of about $0.38 \mathrm{~nm}$ corresponding to the (020) plane in the $\mathrm{WO}_{3}$ identification (Figure 2a). Analyses also showed that the morphology of the $\mathrm{PtWO}_{3}$ conjugates was different than that of their starting $\mathrm{WO}_{3}$ counterparts (Figure 2b). The (111) lattice plane of Pt and its interplanar spacing of $0.23 \mathrm{~nm}$ was identified in Figure 2c.

Figure 2: Physico-chemical signatures of the nanoparticles and nanoparticlesbased hybrids. (a) Raman spectrum of $\mathrm{WO}_{3}, \mathrm{Pt} / \mathrm{WO}_{3}, \mathrm{WO}_{3} / \mathrm{r}-\mathrm{GO}$ and $\mathrm{Pt} / \mathrm{WO}_{3} / \mathrm{r}-\mathrm{GO}$ samples respectively onfirmed the generation of the r-GO-based hybrid materials, with the insert figure showing the characteristic peaks of GO. (b) Attenuated Total Reflectance (ATR) Fourier Transform Infrared spectroscopy (FTIR) allowed direct analyses of the chemical signatures of $\mathrm{WO}_{3}, \mathrm{Pt} / \mathrm{WO}_{3}, \mathrm{WO}_{3} / \mathrm{r}-\mathrm{GO}$ and $\mathrm{Pt} / \mathrm{WO}_{3} / \mathrm{r}-\mathrm{GO}$ nanoparticles and derived hybrids respectively. (c) UV-Vis spectrum of $\mathrm{WO}_{3}, \mathrm{Pt} / \mathrm{WO}_{3}$, $\mathrm{WO}_{3} / \mathrm{r}-\mathrm{GO}$ and $\mathrm{Pt} / \mathrm{WO}_{3} / \mathrm{r}-\mathrm{GO}$ nanoparticles and hybrids respectively. A redshift (shift towards higher wavelengths) was observed for all the nanoparticles and hybrids being tested.

Figure 3: X-ray Photoelectron Spectroscopy (XPS) spectrum of Pt, C, W, O element status in the different samples being investigated. Complementary, characteristic peaks were observed for the r-GO-based hybrids further confirming the templating of the $\mathrm{WO}_{3}$ and $\mathrm{Pt} / \mathrm{WO}_{3}$ onto the $\mathrm{r}-\mathrm{GO}$ surfaces. While Pt coating and $\mathrm{r}-$ GO modification changed the surface chemical/physical properties of the hybrids, did not affect their crystalline structure.

Figure 4: (a) Photocatalytic activities of $\mathrm{WO}_{3}, \mathrm{Pt} / \mathrm{WO}_{3}, \mathrm{WO}_{3} / \mathrm{r}-\mathrm{GO}$ and $\mathrm{Pt} / \mathrm{WO}_{3} / \mathrm{r}-\mathrm{GO}$ nanoparticles and resulting hybrids respectively under visible light irradiation. (b) Kinetic analyses of $\mathrm{WO}_{3}, \mathrm{Pt} / \mathrm{WO}_{3}, \mathrm{WO}_{3} / \mathrm{r}-\mathrm{GO}$ and $\mathrm{Pt} / \mathrm{WO}_{3} / \mathrm{r}-\mathrm{GO}$ samples under visible light irradiation when considering rhodamine $\mathrm{B}$ degradation. 


\section{References:}

[1] Y. Bai, J. Zhang, D.F. Zhou, Y.H. Wang, M. Zhang, P. Wang, Engineering Organic Sensitizers for Iodine-Free Dye-Sensitized Solar Cells: Red-Shifted Current Response Concomitant with Attenuated Charge Recombination, J Am Chem Soc, 133 (2011) 11442-11445.

[2] J.Y. Li, C.Y. Chen, C.P. Lee, S.C. Chen, T.H. Lin, H.H. Tsai, K.C. Ho, C.G. Wu, Unsymmetrical Squaraines Incorporating the Thiophene Unit for Panchromatic Dye-Sensitized Solar Cells, Org Lett, 12 (2010) 5454-5457.

[3] H. Price, E. Lupfert, D. Kearney, E. Zarza, G. Cohen, R. Gee, R. Mahoney, Advances in parabolic trough solar power technology, J Sol Energ-T Asme, 124 (2002) 109-125.

[4] J.E. Pacheco, S.K. Showalter, W.J. Kolb, Development of a molten-salt thermocline thermal storage system for parabolic trough plants, J Sol Energ-T Asme, 124 (2002) 153-159.

[5] R.R. King, D. Bhusari, A. Boca, D. Larrabee, X.Q. Liu, W. Hong, C.M. Fetzer, D.C. Law, N.H. Karam, Band gap-voltage offset and energy production in next-generation multijunction solar cells, Prog Photovoltaics, 19 (2011) 797-812.

[6] B.G. Kim, C.G. Zhen, E.J. Jeong, J. Kieffer, J. Kim, Organic Dye Design Tools for Efficient Photocurrent Generation in Dye-Sensitized Solar Cells: Exciton Binding Energy and Electron Acceptors, Adv Funct Mater, 22 (2012) 1606-1612.

[7] E. Strein, A. Colbert, S. Subramaniyan, H. Nagaoka, C.W. Schlenker, E. Janke, S.A. Jenekhe, D.S. Ginger, Charge generation and energy transfer in hybrid polymer/infrared quantum dot solar cells, Energ Environ Sci, 6 (2013) 769-775.

[8] J. Burschka, N. Pellet, S.J. Moon, R. Humphry-Baker, P. Gao, M.K. Nazeeruddin, M. Gratzel, Sequential deposition as a route to high-performance perovskite-sensitized solar cells, Nature, 499 (2013) 316-+.

[9] M. Fontana, T. Deppe, A.K. Boyd, M. Rinzan, A.Y. Liu, M. Paranjape, P. Barbara, Electron-hole transport and photovoltaic effect in gated MoS2 Schottky junctions, Scientific Reports, 3 (2013).

[10] K. Koci, K. Zatloukalova, L. Obalova, S. Krejcikova, Z. Lacny, L. Capek, A. Hospodkova, O. Solcova, Wavelength Effect on Photocatalytic Reduction of CO2 by Ag/TiO2 Catalyst, Chinese J Catal, 32 (2011) 812-815.

[11] K.G.M. Laurier, E. Fron, P. Atienzar, K. Kennes, H. Garcia, M. Van der Auweraer, D.E. De Vos, J. Hofkens, M.B.J. Roeffaers, Delayed electron-hole pair recombination in iron(III)-oxo metal-organic frameworks, Phys Chem Chem Phys, 16 (2014) 5044-5047.

[12] P.T. Jing, W.Y. Ji, X. Yuan, M. Ikezawa, L.G. Zhang, H.B. Li, J.L. Zhao, Y. Masumoto, Photoinduced Charge Separation and Recombination Processes in CdSe Quantum Dot and Graphene Oxide Composites with Methylene Blue as Linker, J Phys Chem Lett, 4 (2013) 2919-2925.

[13] G. Liu, L.C. Yin, J.Q. Wang, P. Niu, C. Zhen, Y.P. Xie, H.M. Cheng, A red anatase TiO2 photocatalyst for solar energy conversion, Energ Environ Sci, 5 (2012) 9603-9610.

[14] J. Wang, D.N. Tafen, J.P. Lewis, Z.L. Hong, A. Manivannan, M.J. Zhi, M. Li, N.Q. Wu, Origin of Photocatalytic Activity of Nitrogen-Doped TiO2 Nanobelts, J Am Chem Soc, 131 (2009) 12290-12297. [15] W.B. Dai, Y.F. Lei, P. Li, L.F. Xu, Enhancement of photovoltaic performance of TiO2-based dyesensitized solar cells by doping Ca3La3(1-x)Eu3x(BO3)(5), J Mater Chem A, 3 (2015) 4875-4883.

[16] M. Scardamaglia, C. Struzzi, F.J.A. Rebollo, P. De Marco, P.R. Mudimela, J.F. Colomer, M. Amati, L. Gregoratti, L. Petaccia, R. Snyders, C. Bittencourt, Tuning electronic properties of carbon nanotubes by nitrogen grafting: Chemistry and chemical stability, Carbon, 83 (2015) 118-127.

[17] M.X. Guo, M.S. Li, X.Q. Liu, M.L. Zhao, D.J. Li, D.S. Geng, X.L. Sun, H.Q. Gu, N-containing functional groups induced superior cytocompatible and hemocompatible graphene by $\mathrm{NH} 2$ ion implantation, J Mater Sci-Mater M, 24 (2013) 2741-2748.

[18] A.S. Campbell, C. Dong, F. Meng, J. Hardinger, G. Perhinschi, N. Wu, C.Z. Dinu, Enzyme Catalytic Efficiency: A Function of Bio-Nano Interface Reactions, ACS Appl Mater Interfaces, 6 (2014) 5393-5403.

[19] W.C. Lin, Y.J. Lin, Effect of Vanadium(IV)-Doping on the Visible Light-Induced Catalytic Activity of Titanium Dioxide Catalysts for Methylene Blue Degradation, Environ Eng Sci, 29 (2012) 447-452.

[20] F.K. Meng, J.T. Li, S.K. Cushing, M.J. Zhi, N.Q. Wu, Solar Hydrogen Generation by Nanoscale p-n Junction of p-type Molybdenum Disulfide/n-type Nitrogen-Doped Reduced Graphene Oxide, J Am Chem Soc, 135 (2013) 10286-10289.

[21] J.J. Lin, J.X. Shen, R.J. Wang, J.J. Cui, W.J. Zhou, P.G. Hu, D.O. Liu, H. Liu, J.Y. Wang, R.I. Boughton, Y.Z. Yue, Nano-p-n junctions on surface-coarsened TiO2 nanobelts with enhanced photocatalytic activity, J Mater Chem, 21 (2011) 5106-5113.

[22] W.J. Fa, C.Q. Gong, L.H. Tian, T.Y. Peng, L. Zan, Enhancement of Photocatalytic Degradation of 
Poly(vinyl chloride) with Perchlorinated Iron (II) Phthalocyanine Modified Nano-TiO2, J Appl Polym Sci, 122 (2011) 1823-1828.

[23] Z.Z. Yuanhua Sang, Jian Tian, Pin Hao, Haidong Jiang, Hong Liu, Jerome P. Claverie, Enhanced Photocatalytic Property of Reduced Graphene Oxide/TiO2 Nanobelt Surface Heterostructures Constructed by an In Situ Photochemical Reduction Method, Small, (2014).

[24] T.G. Xu, L.W. Zhang, H.Y. Cheng, Y.F. Zhu, Significantly enhanced photocatalytic performance of $\mathrm{ZnO}$ via graphene hybridization and the mechanism study, Appl Catal B-Environ, 101 (2011) 382387.

[25] G.Z. Liao, S. Chen, X. Quan, H.T. Yu, H.M. Zhao, Graphene oxide modified g-C3N4 hybrid with enhanced photocatalytic capability under visible light irradiation, J Mater Chem, 22 (2012) 2721-2726.

[26] S.W. Tong, N. Mishra, C.L. Su, V. Nalla, W.Y. Wu, W. Ji, J. Zhang, Y. Chan, K.P. Loh, HighPerformance Hybrid Solar Cell Made from CdSe/CdTe Nanocrystals Supported on Reduced Graphene Oxide and PCDTBT, Adv Funct Mater, 24 (2014) 1904-1910.

[27] Y. Yan, H. Guan, S. Liu, R. Jiang, Ag3PO4/Fe2O3 composite photocatalysts with an n-n heterojunction semiconductor structure under visible-light irradiation, Ceramics International, 40 (2014) 9095-9100.

[28] F. Kiantazh, A. Habibi-Yangjeh, Ag3VO4/ZnO nanocomposites with an $\mathrm{n}-\mathrm{n}$ heterojunction as novel visible-light-driven photocatalysts with highly enhanced activity, Materials Science in Semiconductor Processing, 39 (2015) 671-679.

[29] M. Shekofteh-Gohari, A. Habibi-Yangjeh, Novel magnetically separable $\mathrm{ZnO} / \mathrm{AgBr} / \mathrm{Fe} 3 \mathrm{O} 4 / \mathrm{Ag} 3 \mathrm{VO} 4$ nanocomposites with tandem n-n heterojunctions as highly efficient visible-light-driven photocatalysts, RSC Advances, 6 (2016) 2402-2413.

[30] V.H. Luan, H.N. Tien, L.T. Hoa, T.M.H. Nguyen, E.S. Oh, J. Chung, E.J. Kim, W.M. Choi, B.S. Kong, S.H. Hur, Synthesis of a highly conductive and large surface area graphene oxide hydrogel and its use in a supercapacitor, J Mater Chem A, 1 (2013) 208-211.

[31] I. Meric, M.Y. Han, A.F. Young, B. Ozyilmaz, P. Kim, K.L. Shepard, Current saturation in zerobandgap, topgated graphene field-effect transistors, Nat Nanotechnol, 3 (2008) 654-659.

[32] B. Marinho, M. Ghislandi, E. Tkalya, C.E. Koning, G. de With, Electrical conductivity of compacts of graphene, multi-wall carbon nanotubes, carbon black, and graphite powder, Powder Technol, 221 (2012) 351-358.

[33] X.Y. Ma, H. Zhang, Fabrication of graphene films with high transparent conducting characteristics, Nanoscale Research Letters, 8 (2013).

[34] R. Stine, W.K. Lee, K.E. Whitener, J.T. Robinson, P.E. Sheehan, Chemical Stability of Graphene Fluoride Produced by Exposure to XeF2, Nano Lett, 13 (2013) 4311-4316.

[35] H. Zhang, X.J. Lv, Y.M. Li, Y. Wang, J.H. Li, P25-Graphene Composite as a High Performance Photocatalyst, Acs Nano, 4 (2010) 380-386.

[36] M.S. Zhu, P.L. Chen, M.H. Liu, Graphene Oxide Enwrapped Ag/AgX (X = Br, Cl) Nanocomposite as a Highly Efficient Visible-Light Plasmonic Photocatalyst, Acs Nano, 5 (2011) 45294536.

[37] Y.B. Tang, C.S. Lee, J. Xu, Z.T. Liu, Z.H. Chen, Z.B. He, Y.L. Cao, G.D. Yuan, H.S. Song, L.M. Chen, L.B. Luo, H.M. Cheng, W.J. Zhang, I. Bello, S.T. Lee, Incorporation of Graphenes in Nanostructured TiO2 Films via Molecular Grafting for Dye-Sensitized Solar Cell Application, Acs Nano, 4 (2010) 3482-3488.

[38] M. Zhang, J. Wu, J. Hou, J.J. Yang, Molybdenum and Nitrogen Co-Doped Titanium Dioxide Nanotube Arrays with Enhanced Visible Light Photocatalytic Activity, Sci Adv Mater, 5 (2013) 535541.

[39] K. Hong, K. Kim, S. Kim, I. Lee, H. Cho, S. Yoo, H.W. Choi, N.Y. Lee, Y.H. Tak, J.L. Lee, Optical Properties of WO3/Ag/WO3 Multi layer As Transparent Cathode in Top-Emitting Organic Light Emitting Diodes, J Phys Chem C, 115 (2011) 3453-3459.

[40] F.G. Wang, C. Di Valentin, G. Pacchioni, Electronic and Structural Properties of WO3: A Systematic Hybrid DFT Study, J Phys Chem C, 115 (2011) 8345-8353.

[41] W. Morales, M. Cason, O. Aina, N.R. de Tacconi, K. Rajeshwar, Combustion synthesis and characterization of nanocrystalline WO3, J Am Chem Soc, 130 (2008) 6318-+.

[42] G. Xin, W. Guo, T.L. Ma, Effect of annealing temperature on the photocatalytic activity of WO3 for O-2 evolution, Appl Surf Sci, 256 (2009) 165-169.

[43] F.G. Wang, C. Di Valentin, G. Pacchioni, Doping of WO3 for Photocatalytic Water Splitting: Hints from Density Functional Theory, J Phys Chem C, 116 (2012) 8901-8909.

[44] M.J. Zhou, J.H. Yan, P. Cui, Synthesis and enhanced photocatalytic performance of WO3 nanorods@graphene nanocomposites, Mater Lett, 89 (2012) 258-261.

[45] K. Wenderich, A. Klaassen, I. Siretanu, F. Mugele, G. Mul, Sorption-Determined Deposition of 
Platinum on Well-Defined Platelike WO3, Angew Chem Int Edit, 53 (2014) 12476-12479.

[46] P.S. Shinde, G.H. Go, W.J. Lee, Multilayered large-area WO3 films on sheet and mesh-type stainless steel substrates for photoelectrochemical hydrogen generation, Int J Energ Res, 37 (2013) 323-330.

[47] S. Nishimoto, T. Mano, Y. Kameshima, M. Miyake, Photocatalytic water treatment over WO3 under visible light irradiation combined with ozonation, Chem Phys Lett, 500 (2010) 86-89.

[48] F.K. Meng, J.T. Li, S.K. Cushing, J. Bright, M.J. Zhi, J.D. Rowley, Z.L. Hong, A. Manivannan, A.D. Bristow, N.Q. Wu, Photocatalytic Water Oxidation by Hematite/Reduced Graphene Oxide Composites, Acs Catal, 3 (2013) 746-751.

[49] N. Naseri, H. Kim, W. Choi, A.Z. Moshfegh, Implementation of Ag nanoparticle incorporated WO3 thin film photoanode for hydrogen production, International Journal of Hydrogen Energy, 38 (2013) 2117-2125.

[50] A. Tanaka, K. Hashimoto, H. Kominami, Visible-Light-Induced Hydrogen and Oxygen Formation over Pt/Au/WO3 Photocatalyst Utilizing Two Types of Photoabsorption Due to Surface Plasmon Resonance and Band-Gap Excitation, J Am Chem Soc, 136 (2014) 586-589.

[51] Y. Sakai, A. Shimanaka, M. Shioi, S. Kato, S. Satokawa, T. Kojima, A. Yamasaki, Fabrication of high-sensitivity palladium loaded tungsten trioxide photocatalyst by photodeposite method, Catal Today, 241 (2015) 2-7.

[52] F. Yang, Y. Takahashi, N. Sakai, T. Tatsuma, Photocatalytic Remote Oxidation Induced by Visible Light, J Phys Chem C, 115 (2011) 18270-18274.

[53] X.M. Su, X.Y. Li, J.J. Li, M. Liu, F.H. Lei, X.C. Tan, P.F. Li, W.Q. Luo, Synthesis and characterization of core-shell magnetic molecularly imprinted polymers for solid-phase extraction and determination of Rhodamine B in food, Food Chem, 171 (2015) 292-297.

[54] W.H. Ping, X.S. Zhu, B.S. Wang, AN IONIC LIQUID LOADED beta-CYCLODEXTRINCROSS-LINKED POLYMER AS THE SOLID PHASE EXTRACTION MATERIAL COUPLED WITH HIGH-PERFORMANCE LIQUID CHROMATOGRAPHY FOR THE DETERMINATION OF RHODAMINE B IN FOOD, Anal Lett, 47 (2014) 504-516.

[55] T. Kornprobst, J. Plank, Photodegradation of Rhodamine B in Presence of $\mathrm{CaO}$ and NiO-CaO Catalysts, International Journal of Photoenergy, (2012).

[56] X.B. Chen, L. Liu, P.Y. Yu, S.S. Mao, Increasing Solar Absorption for Photocatalysis with Black Hydrogenated Titanium Dioxide Nanocrystals, Science, 331 (2011) 746-750.

[57] Y.-Y. Tai, R.-S. Chen, Y. Lin, T.-Y. Ling, M.-H. Chen, FGF-9 accelerates epithelial invagination for ectodermal organogenesis in real time bioengineered organ manipulation, Cell Communication and Signaling, 10 (2012) 34.

[58] J. Boltersdorf, T. Wong, P.A. Maggard, Synthesis and Optical Properties of Ag(I), Pb(II), and Bi(III) Tantalate-Based Photocatalysts, Acs Catal, 3 (2013) 2943-2953.

[59] S.K. Apte, S.N. Garaje, M. Valant, B.B. Kale, Eco-friendly solar light driven hydrogen production from copious waste $\mathrm{H} 2 \mathrm{~S}$ and organic dye degradation by stable and efficient orthorhombic $\mathrm{CdS}$ quantum dots-GeO2 glass photocatalyst, Green Chem, 14 (2012) 1455-1462.

[60] E.R. Nestmann, G.R. Douglas, T.I. Matula, C.E. Grant, D.J. Kowbel, Mutagenic activity of rhodamine dyes and their impurities as detected by mutation induction in Salmonella and DNA damage in Chinese hamster ovary cells, Cancer research, 39 (1979) 4412-4417.

[61] G. Annadurai, R.-S. Juang, D.-J. Lee, Use of cellulose-based wastes for adsorption of dyes from aqueous solutions, Journal of Hazardous Materials, 92 (2002) 263-274.

[62] J.-H. Huang, K.-L. Huang, S.-Q. Liu, A.T. Wang, C. Yan, Adsorption of Rhodamine B and methyl orange on a hypercrosslinked polymeric adsorbent in aqueous solution, Colloids and Surfaces A: Physicochemical and Engineering Aspects, 330 (2008) 55-61.

[63] K. Liu, S. Lin, J. Liao, N. Pan, M. Zeng, Synthesis and Characterization of Hierarchical Structured TiO2 Nanotubes and Their Photocatalytic Performance on Methyl Orange, Journal of Nanomaterials, 2015 (2015) 8.

[64] P. Suresh, A. Umabala, A.P. Rao, Rapid sun light degradation of Rhodamine-B, Methylene blue, Methyl orange, Congo red and their binary mixtures using suprastoichiometric Bi-Molybdate, Int. J. Eng. Appl. Sci, 2 (2015) 42-46.

[65] W.S. Hummers, R.E. Offeman, Preparation of Graphitic Oxide, J Am Chem Soc, 80 (1958) 13391339.

[66] W.Q. Fan, Q.H. Lai, Q.H. Zhang, Y. Wang, Nanocomposites of TiO2 and Reduced Graphene Oxide as Efficient Photocatalysts for Hydrogen Evolution, J Phys Chem C, 115 (2011) 10694-10701.

[67] G. Williams, B. Seger, P.V. Kamat, TiO2-graphene nanocomposites. UV-assisted photocatalytic reduction of graphene oxide, Acs Nano, 2 (2008) 1487-1491.

[68] H.I. Kim, G.H. Moon, D. Monllor-Satoca, Y. Park, W. Choi, Solar Photoconversion Using 
Graphene/TiO2 Composites: Nanographene Shell on TiO2 Core versus TiO2 Nanoparticles on Graphene Sheet, J Phys Chem C, 116 (2012) 1535-1543.

[69] S.H. Zhu, Y.L. Zhu, S.L. Hao, L.G. Chen, B. Zhang, Y.W. Li, Aqueous-Phase Hydrogenolysis of Glycerol to 1,3-propanediol Over Pt-H4SiW12O40/SiO2, Catal Lett, 142 (2012) 267-274.

[70] S.A. Ansari, M.M. Khan, S. Kalathil, A. Nisar, J. Lee, M.H. Cho, Oxygen vacancy induced band gap narrowing of $\mathrm{ZnO}$ nanostructures by an electrochemically active biofilm, Nanoscale, 5 (2013) 9238-9246.

[71] P. Wilhelm, D. Stephan, Photodegradation of rhodamine B in aqueous solution via SiO2@TiO2 nano-spheres, J Photoch Photobio A, 185 (2007) 19-25.

[72] C. Yogi, K. Kojima, N. Wada, H. Tokumoto, T. Takai, T. Mizoguchi, H. Tamiaki, Photocatalytic degradation of methylene blue by $\mathrm{TiO} 2$ film and Au particles-TiO2 composite film, Thin Solid Films, 516 (2008) 5881-5884.

[73] X. Li, J.H. Ye, Photocatalytic degradation of rhodamine B over Pb3Nb4O13/fumed SiO2 composite under visible light irradiation, J Phys Chem C, 111 (2007) 13109-13116.

[74] R. Abe, H. Takami, N. Murakami, B. Ohtani, Pristine simple oxides as visible light driven photocatalysts: Highly efficient decomposition of organic compounds over platinum-loaded tungsten oxide, J Am Chem Soc, 130 (2008) 7780-+.

[75] D. Chen, J.H. Ye, Hierarchical WO3 hollow shells: Dendrite, sphere, dumbbell, and their photocatalytic properties, Adv Funct Mater, 18 (2008) 1922-1928.

[76] C.D. Alan S Campbell, Andrew Maloney, Jeremy Hardinger, Xiao Hu, Fanke Meng, Anthony Guiseppe-Elie, Nianqiang Wu, Cerasela Zoica Dinu, A Systematic Study of the Catalytic Behavior at Enzyme-Metal-Oxide Nanointerfaces, Nanolife, (2014).

[77] S. Wang, T. Wang, Y. Liu, Y.L. Gao, Y.W. Ding, X.F. Xu, X.L. Zhang, W.X. Chen, Visible lightdriven photodecomposition system: preparation and application of highly dispersed Pt-loaded WO3 microparticles, Micro Nano Lett, 6 (2011) 229-232.

[78] S. Rajagopal, D. Nataraj, D. Mangalaraj, Y. Djaoued, J. Robichaud, O.Y. Khyzhun, Controlled Growth of WO3 Nanostructures with Three Different Morphologies and Their Structural, Optical, and Photodecomposition Studies, Nanoscale Research Letters, 4 (2009) 1335-1342.

[79] K.N. Kudin, B. Ozbas, H.C. Schniepp, R.K. Prud'homme, I.A. Aksay, R. Car, Raman spectra of graphite oxide and functionalized graphene sheets, Nano Lett, 8 (2008) 36-41.

[80] S. Stankovich, D.A. Dikin, R.D. Piner, K.A. Kohlhaas, A. Kleinhammes, Y. Jia, Y. Wu, S.T. Nguyen, R.S. Ruoff, Synthesis of graphene-based nanosheets via chemical reduction of exfoliated graphite oxide, Carbon, 45 (2007) 1558-1565.

[81] C. Guery, C. Choquet, F. Dujeancourt, J.M. Tarascon, J.C. Lassegues, Infrared and X-ray studies of hydrogen intercalation in different tungsten trioxides and tungsten trioxide hydrates, J Solid State Electr, 1 (1997) 199-207.

[82] C. Hontorialucas, A.J. Lopezpeinado, J.D.D. Lopezgonzalez, M.L. Rojascervantes, R.M. Martinaranda, Study of Oxygen-Containing Groups in a Series of Graphite Oxides - Physical and Chemical Characterization, Carbon, 33 (1995) 1585-1592.

[83] T.H. Liu, Y.H. Li, Q.J. Du, J.K. Sun, Y.Q. Jiao, G.M. Yang, Z.H. Wang, Y.Z. Xia, W. Zhang, K.L. Wang, H.W. Zhu, D.H. Wu, Adsorption of methylene blue from aqueous solution by graphene, Colloid Surface B, 90 (2012) 197-203.

[84] X.Y. Zhang, Y.J. Sun, X.L. Cui, Z.Y. Jiang, A green and facile synthesis of TiO2/graphene nanocomposites and their photocatalytic activity for hydrogen evolution, International Journal of Hydrogen Energy, 37 (2012) 811-815.

[85] Y.H. Zhang, Z.R. Tang, X.Z. Fu, Y.J. Xu, TiO2-Graphene Nanocomposites for Gas-Phase Photocatalytic Degradation of Volatile Aromatic Pollutant: Is TiO2-Graphene Truly Different from Other TiO2-Carbon Composite Materials?, Acs Nano, 4 (2010) 7303-7314.

[86] F.K. Meng, Z.L. Hong, J. Arndt, M. Li, M.J. Zhi, F. Yang, N.Q. Wu, Visible light photocatalytic activity of nitrogen-doped La2Ti2O7 nanosheets originating from band gap narrowing, Nano Res, 5 (2012) 213-221.

[87] T. Spataru, M. Marcu, L. Preda, P. Osiceanu, J.M.C. Moreno, N. Spataru, Platinum-polytyramine composite material with improved performances for methanol oxidation, J Solid State Electr, 15 (2011) $1149-1157$.

[88] R.S. Vemuri, M.H. Engelhard, C.V. Ramana, Correlation between Surface Chemistry, Density, and Band Gap in Nanocrystalline WO3 Thin Films, Acs Applied Materials \& Interfaces, 4 (2012) 1371-1377.

[89] F.S. Manciu, Y. Yun, W.G. Durrer, J. Howard, U. Schmidt, C.V. Ramana, Comparative microscopic and spectroscopic analysis of temperature-dependent growth of WO3 and W0.95Ti0.05O3 thin films, J Mater Sci, 47 (2012) 6593-6600. 
[90] S. Sakthivel, M.V. Shankar, M. Palanichamy, B. Arabindoo, D.W. Bahnemann, V. Murugesan, Enhancement of photocatalytic activity by metal deposition: characterisation and photonic efficiency of Pt, Au and Pd deposited on TiO2 catalyst, Water Res, 38 (2004) 3001-3008.

[91] M. Vasilopoulou, L.C. Palilis, D.G. Georgiadou, A.M. Douvas, P. Argitis, S. Kennou, L. Sygellou, G. Papadimitropoulos, I. Kostis, N.A. Stathopoulos, D. Davazoglou, Reduction of Tungsten Oxide: A Path Towards Dual Functionality Utilization for Efficient Anode and Cathode Interfacial Layers in Organic Light-Emitting Diodes, Adv Funct Mater, 21 (2011) 1489-1497.

[92] B. Weng, J. Wu, N. Zhang, Y.J. Xu, Observing the Role of Graphene in Boosting the TwoElectron Reduction of Oxygen in Graphene-WO3 Nanorod Photocatalysts, Langmuir, 30 (2014) 55745584.

[93] Y.Y. Liang, H.L. Wang, H.S. Casalongue, Z. Chen, H.J. Dai, TiO2 Nanocrystals Grown on Graphene as Advanced Photocatalytic Hybrid Materials, Nano Res, 3 (2010) 701-705.

[94] J. Kim, C.W. Lee, W. Choi, Platinized WO3 as an Environmental Photocatalyst that Generates OH Radicals under Visible Light, Environ Sci Technol, 44 (2010) 6849-6854.

[95] Y.H. Sang, Z.H. Zhao, J. Tian, P. Hao, H.D. Jiang, H. Liu, J.P. Claverie, Enhanced Photocatalytic Property of Reduced Graphene Oxide/TiO2 Nanobelt Surface Heterostructures Constructed by an In Situ Photochemical Reduction Method, Small, 10 (2014) 3775-3782.

[96] H. Pan, Principles on design and fabrication of nanomaterials as photocatalysts for water-splitting, Renewable and Sustainable Energy Reviews, 57 (2016) 584-601.

[97] Z. Wang, C. Yang, T. Lin, H. Yin, P. Chen, D. Wan, F. Xu, F. Huang, J. Lin, X. Xie, H-Doped Black Titania with Very High Solar Absorption and Excellent Photocatalysis Enhanced by Localized Surface Plasmon Resonance, Adv Funct Mater, 23 (2013) 5444-5450.

[98] Z. Zhang, L. Zhang, M.N. Hedhili, H. Zhang, P. Wang, Plasmonic gold nanocrystals coupled with photonic crystal seamlessly on $\mathrm{TiO} 2$ nanotube photoelectrodes for efficient visible light photoelectrochemical water splitting, Nano Lett, 13 (2012) 14-20.

[99] F. Iskandar, A.B.D. Nandiyanto, K.M. Yun, C.J. Hogan, K. Okuyama, P. Biswas, Enhanced photocatalytic performance of brookite $\mathrm{TiO} 2$ macroporous particles prepared by spray drying with colloidal templating, Adv Mater, 19 (2007) 1408-+.

[100] S. Horikoshi, A. Saitou, H. Hidaka, N. Serpone, Environmental remediation by an integrated microwave/UV illumination method. V. Thermal and nonthermal effects of microwave radiation on the photocatalyst and on the photodegradation of rhodamine-b under UV/Vis radiation, Environ Sci Technol, 37 (2003) 5813-5822.

[101] Y. Park, Y. Na, D. Pradhan, B.-K. Min, Y. Sohn, Adsorption and UV/Visible photocatalytic performance of $\mathrm{BiOI}$ for methyl orange, Rhodamine B and methylene blue: Ag and Ti-loading effects, CrystEngComm, 16 (2014) 3155-3167.

[102] Y. Na, Y.-I. Kim, D. Won Cho, D. Pradhan, Y. Sohn, Adsorption/photocatalytic performances of hierarchical flowerlike BiOBrxC11-x nanostructures for methyl orange, Rhodamine $\mathrm{B}$ and methylene blue, Materials Science in Semiconductor Processing, 27 (2014) 181-190. 